\title{
El hacha decimonónica: EI avance silencioso de la deforestación en Costa Rica entre 1821-1900
}

Recibido: 3 de septiembre 2019 Revisado: 28 de febrero 2020 Aprobado: 2 de marzo 2020

Maximiliano López López Costarricense. Máster en Historia Aplicada y Máster en Pedagogía con énfasis en Atención a la Diversidad. Es profesor de la Escuela de Historia de la Universidad Nacional de Costa Rica, Costa Rica, e Investigador del Observatorio de Historia Agroecológica y Ambiental (OHAA) adscrito a la Maestría en Historia de esa misma Escuela. También participa de la Sociedad Latinoamericana y Caribeña de Historia Ambiental (SOLCHA) y es cofundador de la Red Centroamericana de Investigación y Docencia en Estudios Sociales y Ciudadanía Crítica (RECIDEC).

Correo electrónico: maxmlopez6@gmail.com

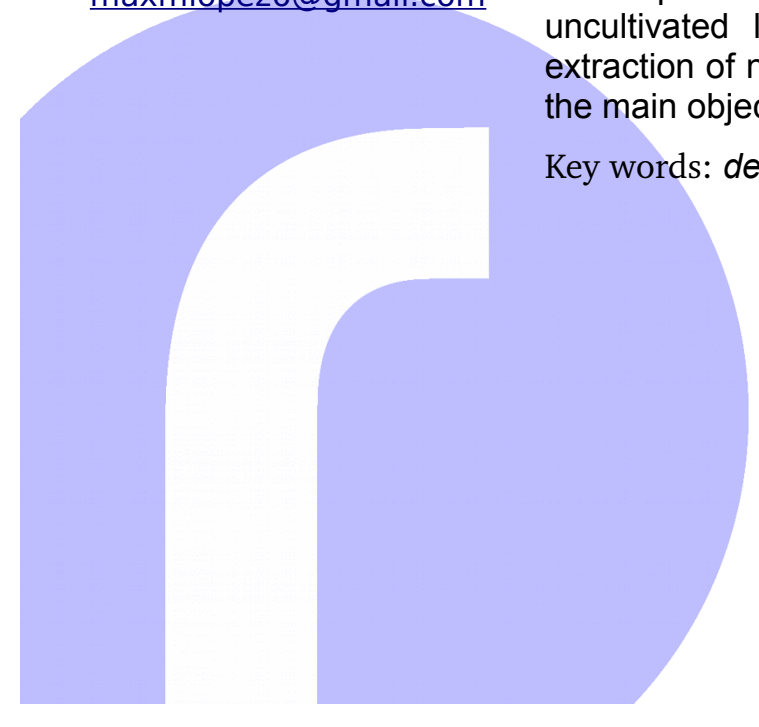

https://revistas.uned.ac.cr/index.php/rupturas (c) (i) (2)
Resumen: Este trabajo aborda el problema de la deforestación en Costa Rica, desde los albores de la independencia hasta el cierre del siglo XIX. A pesar de la escasez de fuentes y la limitada existencia de estadísticas relativas a esta materia, se busca evidenciar que la deforestación del siglo XIX, aunque de pequeña escala, tuvo fuertes repercusiones sobre la cobertura forestal, especialmente en lo relativo a maderas finas de alta rentabilidad, y sentó las bases para la industria maderera que cobró vigor en el siglo XX. Desde esta perspectiva, el artículo también demuestra que existía evidencia sobre las repercusiones del patrón de explotación forestal impulsado por particulares y por el mismo Estado en el territorio nacional, tal aspecto, sin embargo, no fue tenido en cuenta por los intereses económicos que recaían sobre los baldíos y los bosques nacionales en una época en la cual la extracción de la riqueza nacional y su puesta en el mercado eran los objetivos fundamentales.

Palabras clave: deforestación; bosques; madera; conservación, Costa Rica

\section{$19^{\text {th }}$ century's axe: Costa Rica's silent deforestation creep between 1821 and 1900}

Abstract: This article deals with the problem of deforestation in Costa Rica, from the early stages of independence to late $19^{\text {th }}$ century. In spite of the scarce sources and statistics dealing with the issue, this work seeks to show that $19^{\text {th }}$ century deforestation, though small in scale, impacted forest areas strongly, especially high-yield fine timber, and claid the foundation of the timber industry that picked up steam in the $19^{\text {th }}$ century. The article also demonstrates that there was evidence on the repercussions that the exploitation pattern which was fostered by both private citizens and the State. This aspect was, however, not ignored because of the economic interests that uncultivated land and national forests represented at a time when the extraction of national resources and their subsequent sale in the market were the main objectives.

Key words: deforestation; forests; timber; conservation; Costa Rica 
La industria del corte de maderas, esa pingüe fuente de riqueza pública, quedará, pues, cegada por largo tiempo, pero no por siempre: los bosques se repueblan por sí mismos, y día llegará en que alzados los precios ó renovadas las maderas vuelva a ser esa industria el venero rico del Guanacaste (Zúñiga, 1904, X).

\section{Introducción}

Existe abundante literatura sobre la historia costarricense tanto de la época colonial como de su etapa republicana, la mayoría enfocada al estudio de aspectos sociales, culturales, políticos y económicos, no así de temas ambientales. Asimismo, la mayor parte de tales estudios se centró en analizar la realidad del Valle Central y la expansión del cultivo del café en la medida que este cultivo fue creando procesos de aparente concentración de tierras, proletarización, migraciones hacia la frontera agrícola y, en general, una división social del trabajo, particularmente después de la llegada del capital británico y la existencia de capital comercial que dio un fuerte impulso al desarrollo económico nacional.

En este marco, las interpretaciones sobre el avance de la deforestación han estado vinculadas al desarrollo de la caficultura, la ocupación de tierras de frontera agrícola y el crecimiento de la actividad ganadera, o del cultivo del banano hacia fines del XIX. Poco se ha escrito sobre la dinámica adoptada por la explotación forestal y, aunque se conoce que la exportación de madera fue común desde mediados del siglo XIX, no existe aún un trabajo de base que se haya dado a la tarea de reconstruir y cuantificar la importancia de ese flujo comercial.

No obstante, iniciamos este capítulo con una cita de 1904, la cual es elocuente respecto de lo ocurrido con los bosques costarricenses al menos durante la segunda mitad del siglo XIX y en particular de su efecto en Guanacaste, pero también de los condicionantes externos (precio) que marcaban la pauta de ese trasiego de recursos naturales. Las fuentes con las que se decidió hacer este acercamiento al proceso de deforestación son principalmente primarias, entre ellas actas municipales, leyes y decretos, lo mismo que memorias institucionales en las cuales se discutía sobre el problema, pues interesa rescatar visiones más cualitativas sobre lo que se ha dicho en otros trabajos usando estudios cuantitativos.

Del panorama historiográfico que aborda esta temática, y por la cercanía al enfoque aquí propuesto, es absolutamente necesario rescatar dos obras que se centran en este tipo de lecturas. Una de ellas es la obra de Boza (2015), Historia de la Conservación de la Naturaleza en Costa Rica: 1754-2012, en la que se hace un recuento minucioso de fuentes históricas, periodísticas y legales relacionadas con el tema de la conservación dentro de la cual hay gran 
cantidad de referencias al tema de la deforestación en particular. La otra obra, de trascendental importancia para comprender la dinámica de los bosques y la deforestación en Costa Rica se titula Los bosques del progreso. Explotación forestal y régimen ambiental en Costa Rica: 1883-1955, escrito por Goebel (2013) como resultado de su estudio doctoral. El trabajo de Goebel, que solo aborda una parte del siglo XIX, se centra en analizar la deforestación como respuesta a los mecanismos de oferta y demanda del mercado de la madera y propone, entre otras cosas, que este proceso se constituyó en la "entrada definitiva" de Costa Rica en la dinámica del mercado mundial. Aunque este trabajo comulga con los planteamientos de Goebel, en realidad se trata de un abordaje que intenta poner de manifiesto las dinámicas internas de esa deforestación, las lógicas estatales y la percepción ciudadana sobre algunas de las manifestaciones particulares que adoptó dicha práctica. Además, como es válido reiterar, las estadísticas nacionales solo empezaron a registrarse a finales de la década de 1880; por tanto, la reconstrucción de 1821 en adelante debe recurrir necesariamente a elementos de corte cualitativo, tanto en fuentes primarias como secundarias.

Dicho esto, es importante recalcar que aventurarse a releer el pasado nacional en clave ambiental tiene como propósito colaboró con la construcción de conocimiento que ayude a comprender las dinámicas socioecológicas, cuya evolución de alguna manera contribuyó a configurar los agroecosistemas del Valle Central, así como de regiones periféricas, entre ellas el Pacífico Norte, vistos en la larga duración. Con este propósito en mente, el presente trabajo ofrece un acercamiento a las situaciones que marcaron el proceso de deforestación, desde la independencia hasta finales del siglo XIX; pasando de las políticas que incentivaban la ocupación del territorio con fines productivos a las ideas de progreso del orden liberal y de la penetración del capitalismo agrario más allá del Valle Central. Desde esta perspectiva, el trabajo también aporta a comprender una complejidad mayor relacionada con la aparición de los intereses por conservar la naturaleza, proteger las fuentes de agua e incluso impulsar la reforestación, entre otros aspectos, para promover de este modo la gestión del bosque comprendiéndolo como un sistema complejo donde interactúan múltiples componentes, pero teniendo como norte su conservación.

Pero este panorama también resulta vital para comprender lo que más adelante, en el siglo XX, serían los primeros intentos por crear áreas protegidas, el vínculo que se sugería entre estas y el turismo, la consolidación de iniciativas de conservación particularmente desde la década de 1960 y la promulgación de leyes específicas como la Ley Forestal de 1969, por citar algunos ejemplos. Por último, aunque no menos importante, este artículo también busca aportar, desde el punto de vista pedagógico y mediante un relato descriptivo-explicativo, a la comprensión de esta temática en aquellas áreas donde el estudio de los temas ambientales tiene importancia curricular. 


\section{Entre la herencia colonial y el progreso liberal}

Como punto de partida, se debe indicar que el deterioro del ambiente en nuestro territorio tiene sus raíces en la época colonial, proceso que se agravó después de la independencia, particularmente por la vinculación al mercado mundial. Dada su naturaleza agrícola y su inserción al mercado como proveedor de materias primas, Costa Rica impulsó decididamente la exportación de café desde mediados del siglo XIX, lo cual llevó a una expansión acelerada del cultivo en el centro del país. Dicho proceso no solo incidió sobre los bosques, charrales y otras áreas incultas, sino que también ocasionó un impacto directo en las zonas de recarga acuífera y sobre el caudal y calidad del agua de los ríos, como consecuencia del deficiente manejo de las llamadas "aguas mieles", resultantes de los procesos de beneficiado del grano.

De igual forma, la paulatina ocupación del territorio, y consecuentemente la existencia de una rica frontera agrícola, motivaron la exportación de maderas finas, lo que se constituyó en un pilar de la economía costarricense, como veremos más adelante. Sobre esto último, es pertinente señalar que la deforestación no es atribuible solo al hacha y la sierra del campesino o del ganadero, sino que respondió a lógicas diversas en las cuales también participó el capital oligárquico que se fundó sobre el control de la producción y comercialización del denominado grano de oro.

Respecto a la explotación de la madera, es necesario, antes que nada, hacer tres acotaciones de partida. Lo primero es que la visión de la naturaleza como una barrera para el desarrollo fue común en toda América Latina y, como consecuencia de ello, es usual encontrar alusiones al bosque o a las montañas como una "naturaleza feraz" que debía ser vencida en nombre del desarrollo-progreso, particularmente en la segunda mitad del siglo bajo estudio. En segundo lugar, es importante señalar que el aprovechamiento de la madera como mercancía para la exportación fue común desde mediados del siglo XIX, al punto de representar un aporte significativo entre el total de las exportaciones. Finalmente, mientras que la madera del Valle Central parece haber constituido la principal fuente de materia prima para la construcción y la ebanistería, la madera para exportación se tomó fundamentalmente de las zonas más cercanas a las costas por la facilidad de su transporte hasta los embarcaderos, en especial en el Pacífico Norte y Central, como veremos luego.

Carolyn Hall señala que, hacia el final del dominio español, todavía predominaba en Costa Rica un "panorama de densa selva" y que "la mayor parte de la tierra estaba sin cultivar" (Hall 1991, 25). Esta perspectiva de Hall puede aceptarse como válida siempre y cuando el análisis o escala de observación sea nacional, pues existe documentación que atestigua, para una escala regional, una situación distinta en aspectos relativos a bosques y maderas en la época de la independencia en el Valle Central. Por ejemplo, en mayo de 1821, el cabildo de San José acordaba "instar al pueblo a hacer plantíos de cedro ya que ha carecido de esta madera tan útil para construcciones" 
(ANCR, Municipal 1821, 000485). La sola noción de carencia de madera de cedro es un claro indicio de la explotación a la que estuvo sometido ese recurso en la época previa a la independencia, particularmente en las zonas cercanas a los principales centros de población.

Esa preocupación por la escasez de cedro también explica que, en 1828, el gobierno estableciera, mediante Decreto 161, que les correspondía a las municipalidades ocuparse de "La conservación y repoblación de montes y plantíos del común" (Sancho 1972, 73). En esa misma línea, y solo un año después de ese decreto, la municipalidad de Heredia ${ }^{1}$ conformaba una comisión para investigar la tala de árboles (ANCR, Municipal 1929, 000359), mientras que, en 1844, la municipalidad de Aserrí exponía la carencia de leña y maderas en el común del pueblo (ANCR, Municipal 1844, 000432). Igualmente, en ese mismo año, en la municipalidad de San José se indicaba que no se debían repartir los parajes denominados "Isla del Virilla"2 y "Cedro de los Indios", el primero por ser el sitio donde los vecinos obtenían la madera que necesitaban y el segundo por tener valiosas maderas (ANCR, Municipal 1844, 000471).

Para cerrar con estos ejemplos, es también oportuno recordar que, en 1847, el municipio de Heredia recibía las denuncias por el destrozo de montañas en San Rafael, en claro incumplimiento de lo dispuesto en el Decreto 161 citado (ANCR, Municipal 1847, 000632). Poco después, en 1855, en la municipalidad de Paraíso se indicaba que los montes con disponibilidad de leña se encontraban cerrados en claro perjuicio de los vecinos (ANCR, Municipal 1955, $000741,20 \mathrm{v}$ ). Estas evidencias hablan claramente de un activo proceso de tala en el Valle Central, y especialmente aluden a la dificultad para contenerlo. Así, esta preocupación tan temprana en el siglo XIX conduce a plantearse la hipótesis de que si la leña y la madera de cedro ya escaseaba, a pesar de la poca población que tenía el país para entonces, sería plausible señalar que esto obedecía a la extracción realizada de forma intensiva de estos recursos desde antes de la independencia. Por otro lado, este interés por el cedro hace suponer que ya se tenía un amplio conocimiento sobre las propiedades físico-mecánicas de esta madera, tales como la resistencia a las condiciones climáticas, a las plagas $\mathrm{y}$, por supuesto, su versatilidad en labores de construcción y elaboración de muebles.

Ahora bien, esa necesidad por controlar la corta y el uso de las maderas se fue tornando en una necesidad cada vez más apremiante para el gobierno y los municipios. El Decreto XXV del 28 de mayo de 1831, bajo el título "Se crian fondos de propios para el pueblo de la Union", en su artículo 8 establecía que la Municipalidad "nombrará un comisionado que se pagará á juicio de la misma, en arreglo á su trabajo; siendo á su cargo el valúo y venta de las maderas, y cuidar de su estraccion" (Leyes y decretos 1831-1832, 79). De la misma forma, y tan solo dos años después, la Municipalidad de La Unión "acordó prohibir que derriben los árboles de cedro, ya que se están agotando" (ANCR, Municipal 1833, 000409).

La continua tala, y el limitado éxito del Decreto 161, originó que, en 1833, el Mando Político Superior emitiera una disposición que pedía sembrar o man-
1. Para profundizar en el caso de Heredia, puede verse el trabajo de maestría de Marisol Morera, sobre Los orígenes del discurso conservacionista en Costa Rica: Estudio de caso de Heredia (1821-1840). En que la autora aborda la naturaleza de los conflictos de carácter ecológico-distributivos que se empezaban a gestar, particularmente sobre el recurso hídrico y los bosques.

2. En el caso de la "Isla del Virilla", se tiene referencias de que correspondía a la zona del Común de Tibás. 
tener 25 árboles de "maderas útiles" por cada manzana de tierras del común que se tuvieran en explotación. Del mismo modo, y en procura de resolver la posible carencia de recursos ante el aumento de la población, el Decreto XXI del 9 de mayo de 1833 mediante el que se entregaban tres leguas de tierra a las ciudades de San José, Cartago y Alajuela, establecía en su artículo 5 que le correspondía a las municipalidades proceder "desde luego por cuenta de sus fondos á la plantacion de cedros, guachipelines, y otras maderas necesarias para la edificacion" (Leyes y decretos 1833-1836, 46).

Hay evidencias de que esta preocupación por la escasez de madera, y en particular el comunicado del Mando Político Superior, fue discutido en cabildos como La Unión, Cartago, Quircot, Paraíso y Esparza, entre otros, desde los cuales se dispuso de diversos mecanismos para enfrentar la situación (ANCR, Municipal 1833, 000342, 013511, 000199, 000555, 000303). Queda claro con estos ejemplos que el interés por disponer de maderas no solo apuntaba a la construcción de casas y muebles, sino también de edificaciones públicas, dado que el país empezaba a organizarse política y administrativamente, lo cual demandaba muchos recursos. Sin embargo, tampoco puede dejarse pasar de manera desapercibida que en estas disposiciones se empiezan a emitir recomendaciones específicas relacionadas con "plantar árboles útiles" (lo que sería hoy reforestación), aspecto que será recurrente en otras directrices del periodo.

De forma paralela al interés por asegurarse la protección y aprovisionamiento de madera, también se hizo evidente la vinculación entre la cobertura forestal y la existencia de recurso hídrico. Solo un año después de que el Mando Político dispusiera sembrar o mantener árboles en las tierras comunes, la Municipalidad de Esparza emitía un "Acuerdo municipal reglamentando la tala de árboles a la orilla de los ríos y quebradas" (ANCR, Municipal 1834, 000509). Algo semejante hizo la de Heredia, en 1847, debido a la denuncia citada anteriormente, pues dispuso nombrar una comisión "encargada de examinar la tala de árboles, en las márgenes de los ríos, la cual está prohibida por ley". Y en ese mismo contexto, la aparente presión que se empezaba a vivir en el Valle Central, tanto por la expansión del café como por el mismo aumento de la población y la escasez de recursos, originó que el gobierno emitiera algunas disposiciones con el fin de que la población se decidiera a ocupar otras partes del territorio.

Es así como desde 1840, el Decreto 14 del 26 de febrero, por ejemplo, señalaba que era necesario activar el puerto de Puntarenas y, en consecuencia, señalaba que quienes se establecieran en terrenos baldíos cerca del Golfo podrían "disponer libremente de las maderas que hubiesen de cortar para hacer los desmontes, y harán ademas suyo todo el terreno que cultiven en diez años contados desde hoy, cualquiera que sea el fruto ó planta cultivada" (Leyes y decretos 1839-1840, 303). Como se aprecia en este caso y en otros que se anotarán adelante, la madera tenía la connotación de premio o recompensa por el esfuerzo de poblamiento, lo cual también hace notar que ya este era un bien altamente cotizado y que posiblemente era, junto con la tierra misma, un aliciente para promover la empresa colonizadora. A esto debe 
sumarse que las tierras ofrecidas en recompensa se ubicaban cerca de las costas, ello implicaba que dicha madera podía ser embarcada y exportada con facilidad. Desde este punto de vista, resulta comprensible que la relación sociedad-naturaleza surgida de estas disposiciones adquiriera un matiz netamente extractivista de recursos del bosque, especialmente maderables.

Entretanto, en el Valle Central, el Decreto XXXV del 18 de diciembre de 1841 emitía el Reglamento de Policía, mediante el cual se creaba el Reglamento para la administración local de los departamentos. En el capítulo III de ese documento, se establecía lo relativo a la reducción a dominio particular de los terrenos que habían pertenecido al común de los pueblos, barrios y cuarteles, lo que podría entenderse, según Acuña y Molina $(1986,54)$, como la transformación de las formas coloniales en la "propiedad típicamente capitalista". Concretamente, el artículo 21 de dicho capítulo señalaba que en aquellos terrenos aún bajo dominio del común:

debe separarse una parte, que no baje de diez manzanas contiguas ó separadas, para cultivar en ellas esclusivamente las maderas de construccion; á saber: caoba, cedro, cucaracha, ronron, guapinol, cocobolo, ira, quizarrá, laurel, guachipelin, madera negra, brazil clavoso, raton negro ó colorado, y cirrí colorado: el cultivo se costeará por los fondos municipales (Leyes y decretos 1841-1842, 211).

Es admisible pensar que este proceso de "privatización" de la propiedad comunal motivó a muchos costarricenses a involucrarse en las iniciativas de ocupación de otras regiones del territorio, bien para sembrar cultivos como café y caña en la periferia del Valle Central o para habilitar las costas, según lo propuesto en el Decreto 14 de 1840. Al menos, en teoría, pareciera que tales disposiciones lograron su cometido y alentaron la ocupación de terrenos y la explotación de maderas cerca del Golfo de Nicoya, pues así lo ilustra la información descrita por Felipe Molina en lo que algunos consideran la primera obra formal sobre historia de Costa Rica, Bosquejo de la República de Costa Rica seguido de apuntamientos para su historia. Teniendo el debido cuidado de no caer en las idealizaciones propias de estas obras del siglo XIX, es absolutamente relevante destacar que, según Molina:

Toda la costa del Golfo de Nicoya está cubierta de bosques de cedro, caoba y otras maderas que se cortan y asierran en máquinas, movidas por agua ó por bestias, que hay establecidas alli, para enviar cargamentos al Perú, Chile y California (Molina 1851, 34). 
Esta referencia a la extracción de madera de las costas del Golfo de Nicoya es reveladora en varios sentidos. En primera instancia, deja claro que, independientemente de la magnitud de dicha explotación, desde muy temprano en la vida republicana, el comercio de la madera fue cobrando auge en regiones periféricas, de forma particular en el Pacífico Norte. En segundo lugar, es evidente la existencia de un activo comercio maderero con distintas regiones del continente americano, a donde se enviaban maderas finas como cedro y caoba. Y, en tercer lugar, indica que el aserrío de la madera ya se hacía con "máquinas" y no simplemente con sierras manuales, lo cual habla de los avances en la industria maderera que iría cobrando cada vez más fuerza. Dada la existencia de estas "máquinas", es probable que dicha tecnología asociada al aserrío y exportación de madera haya estado vinculada a la inversión de capitales procedentes del Valle Central o de los principales hacendados del Pacífico Norte asentados en las viejas haciendas coloniales, o incluso favorecida por el acceso a algún tipo de crédito. Autores como Gudmundson (1979), Sequeira (1985) y Edelman (1998) han señalado que muchos de los hacendados cafetaleros estuvieron vinculados o, en algunos casos, jugaron más de un rol con actividades como la ganadería, minería e incluso el cultivo de la caña, durante distintos momentos del siglo XIX. Aunque hay poca información para el periodo, pareciera que dicha explotación también pudo ser promovida por capital extranjero vía contratos con el Estado.

\section{El control sobre la explotación maderera}

Ahora bien, si reconocemos el lento desarrollo de las comunicaciones terrestres durante el siglo XIX, y que la mayoría de los esfuerzos estuvieron dirigidos a habilitar el tránsito del café hacia Puntarenas, es perfectamente comprensible que, en muchos casos, la explotación maderera no fuese del conocimiento de las autoridades o simplemente escapase a su inspección debido a la poca cantidad de personal de que se disponía para el control fiscal. Prueba de esto es el Decreto $\mathrm{N}^{\circ} 2$ del 7 de marzo de 1853, en el cual el presidente Juan Rafael Mora señalaba que, en atención a la tala de maderas cerca de las costas sin ningún provecho para el país, se prohibía "la exportación de maderas de cedro y caoba en trozos de más de doce pulgadas de grueso, cortadas en terrenos baldíos, ó en la milla reservada por el Gobierno a favor de los navegantes, pescadores y salineros" (Leyes y decretos 18511853, 224).

Pero ese decreto, además de poner coto a la evasión del pago de impuestos, deja claro que, para mediados del siglo XIX, el Estado tenía "montada" una estructura de contratos para la exportación de maderas nacionales, pues daba un plazo de gracia para quienes ya tenían contratos de explotación de maderas mayores a ese diámetro. La posibilidad de que parte de la tala y exportación de maderas desde las costas costarricenses se autorizara por vía de contratos refuerza la premisa de que estos cortes no fueron producto de 
una simple expansión de frontera agrícola en manos de campesinos, sino que respondió más a una actividad comercial con alta inversión ${ }^{3}$. Por ejemplo, en 1855, C. Cushing, quien era agente de la Compañía Accesoria del Tránsito con operaciones en el río San Juan, señalaba, mediante un comunicado a Thomas Lord (vicepresidente de la Compañía), que el corte de maderas en Ometepe resultaba demasiado oneroso para la Compañía, pues el monto entre herramientas, transportes y adelantos llegaba a la suma de 12 mil dólares (ANCR, SECGYM 1855, 9-10) ${ }^{4}$. Esta evidencia, aunque no corresponde a la explotación de maderas en nuestro territorio, es ilustrativa de lo que representaba en costos la operación maderera, y es válida en términos comparativos dada la cercanía geográfica y las características forestales de la cuenca del río San Juan.

Pero, así como este, otro ejemplo interesante relacionado con el control que el gobierno intentaba establecer sobre la explotación y el uso de la madera lo constituye el Decreto $\mathrm{N}^{\circ} 3$ del 16 de octubre de 1855 . Mediante este documento, el presidente Mora atendía la necesidad de estimular la actividad minera en Moracia $^{5} \mathrm{y}$, para ello, señalaba que:

El Gobierno concede á cada distrito de minas el uso esclusivo de las maderas de construcción y útiles para ademes que encuentren en tierras baldías dentro el radio de una legua del centro de cada distrito. Por consiguiente es prohibido á cualquiera persona derribar árboles, dentro de los límites demarcados, para otros usos que no sean en favor de las minas (Leyes y decretos 1854-1855, 170). ${ }^{6}$

Esta idea de explotar la madera de los bosques nacionales no tenía solo un sentido utilitarista, pues como ya se evidenció, y como lo exponen algunos escritos de la época, el "valor" asignado a esta actividad era cada vez mayor. Sin embargo, en las decisiones emitidas desde las autoridades también era común encontrar "aparentes contradicciones" pues, por ejemplo, solo cuatro años después de la prohibición antes citada, el gobierno autorizaba la exportación irrestricta de madera en el Pacífico Norte. Lo interesante de este nuevo decreto es que, en su argumentación, el presidente decía:

Con la mira de ensanchar el comercio de esportacion con el producto de los inmensos bosques que posee la República en la parte occidental de su territorio; y de proveer, por este medio, á la Provincia de Moracia de fondos para que fomente la instrucción pública, decreto: Art. $1^{0}$. Es

3. Para profundizar en aspectos relativos a costos y rentabilidad de la exportación de maderas para finales del siglo XIX y primera mitad del $X X$, puede verse la obra de Goebel Los bosques del progreso, citada anteriormente.

4. Se refiere a la Secretaría de Guerra y Marina.

5. Moracia es el nombre con el que se conoció a la actual provincia de Guanacaste entre 1854 y 1860 , durante el mandato de Juan Rafael Mora Porras.

6. Ya en la Ordenanza de Minería (Decreto 216 de mayo de 1830, 207-248), la sección décima sobre Policía y gobierno interior del mineral hablaba de tres departamentos de minería: Corralillo, Quebrada-onda y Machuca. 
permitida por el término de cinco años la esportacion de maderas en bruto de cualquier dimension y calidad, por los diversos embarcaderos de la costa del Pacífico situados desde Caboblanco hasta el Golfo de Salinas, sin otros derechos que los que el presente decreto establece. Art. $2^{0}$. Por cada troza de madera que, en virtud del artículo anterior, se embarque en los puntos de la costa comprendidos en la jurisdiccion de la Provincia de Moracia, se cobrarán dos reales, sea cual fuere su dimensión; debiendo pagarse previamente á su embarque (Leyes y decretos 1859-1860, 3-4).

No obstante, mientras se autorizaba dicha actividad en el Pacífico, establecía restricciones severas a esta actividad en el Caribe. En este caso, quizá debido a que la actividad estaba escapando a su control y, especialmente, al cobro de los impuestos. Ante esto, en marzo de 1859, el Gobierno señalaba:

Teniendo noticia de que sobre las májenes del Sarapiquí, y en otros puntos del territorio de la República en la costa del Atlántico se han establecido cortes de madera sin permiso del Gobierno, y que á pesar de las prevenciones de las autoridades de la frontera se continúa tan ilegal tráfico, decreto: Art. $1^{0}$. Desde el $1^{0}$ del mes de Abril próximo en adelante no se permitirá en el territorio de la República, sobre la costa del Atlántico, ningún corte de madera para la exportación, sin el espreso permiso del Gobierno. [...] Artículo $2^{0}$. Por cada vara de largo que tenga la troza, sea cual fuere su grueso, pagará el exportador medio real (Leyes y decretos 1859, 14-15).

Esta aparente contradicción del gobierno debe analizarse en el marco de una actividad extractiva que venía creciendo significativamente tanto en el Pacífico Norte (donde se había consolidado gracias a las políticas destinadas a habilitar el puerto de Puntarenas) como en el Caribe, y de la cual el Estado podría tener información por los contratos vigentes. Pero, esencialmente, hay que comprenderla como un claro interés por controlar el comercio de la madera en tanto ya constituía una fuente de tributos que se escapaba al control 
estatal. De hecho, tal vez por esta razón, y con la idea de equilibrar las decisiones aplicadas en otras partes del país, en 1861 se derogó el decreto que permitía la exportación irrestricta de madera del Pacífico y se homogenizó a dos reales el impuesto por cada troza de madera exportada desde cualquier puerto del Pacífico (Leyes y decretos 1861-1862, 10). Sin embargo, la restricción a la explotación de madera en el Caribe no fue efectiva y, en 1869, un nuevo decreto, emitido por Jesús Jiménez como presidente provisional, decía en su artículo 1:

Es prohibida la exportacion por la via de San Juan de Nicaragua de las maderas, zarza parrilla, hule ó goma elástica, bálsamos recinas y cualesquiera otros productos naturales que se corten, extraigan ó recojan de los bosques en las tierras baldías de la República, comprendidos entre la cordillera de los Andes ${ }^{7}$ y las playas del Atlántico, sin autorización prévia del Juez de Hacienda, á virtud de contrata celebrada por acuerdo del Gobierno en pública subasta; y es por tanto prohibida la esplotacion de estas materias en la extension indicada, con la mira de exportarlas (Leyes y decretos 1869, 90).

De nueva cuenta, este decreto es claro en la importancia que tenía para el Gobierno el controlar, vía contratos, la explotación de los recursos de la naturaleza y asegurarse por este medio la captación de recursos en subasta pública, así como los impuestos correspondientes a la exportación. Pero, por otra parte, esta clase de ejemplos llevan a reafirmar que la administración, y especialmente la vigilancia del territorio, era insuficiente para controlar la explotación forestal, por lo que se favorecía su "explotación silenciosa e ilegal". De hecho, aunque en las décadas de 1850 y 1860 hay denuncias por temas relativos a maderas, es hasta en la segunda mitad del siglo XIX que aparecen expedientes judiciales de forma regular por casos de aparente deforestación o comercio ilegal de madera ${ }^{8}$. Así, por ejemplo, en 1870 se dicta condena contra varias personas por tala ilegal en Bajos del Poás (ANCR, SECPOL $1870,008825)^{9}$ y, en 1874 , la Agencia de Policía de Alajuela abre investigación contra un guardabosque por la venta ilegal de maderas (ANCR, SECPOL 1874, 009948).

En este desarrollo, la región de Guanacaste fue una de las zonas donde la corta de madera se convirtió en una actividad de gran auge, incluso por encima de la ganadería misma. Por ejemplo, Calvo $(1886,194)$, al referirse a las zonas de Liberia, Nicoya, Santa Cruz, Bagaces y Cañas, señalaba que "Grandes haciendas de ganado é importantes cortes de madera, son los principales ramos á que en aquellas poblaciones se da preferente atención". En

\begin{abstract}
7. La identificación del sistema montañoso de Costa Rica como parte de "Los Andes" no es común en los textos históricos, pero según la opinión del historiador José Antonio Fernández Molina, parece que existía la noción de que el lago de Nicaragua y el río San Juan constituían el corte natural entre los sistemas de la Sierra Madre de México y los Andes.
\end{abstract}

8. A inicios del siglo $X I X$, se presentaban denuncias especialmente ante las municipalidades.

9. Corresponde a la Secretaría de Policía. 
este sentido, también es pertinente señalar que, según la reconstrucción de estadísticas parroquiales del siglo XIX, hecha por Pérez Brignoli (1988), particularmente referida a los bautizos registrados, cantones como Nicoya y Santa Cruz mostraban una dinámica poblacional mucho mayor que algunos cantones del Valle Central.

Probablemente, este dinamismo poblacional cobró mayor importancia desde la década de 1850, debido a factores asociados al desarrollo del capitalismo agrario en el Valle Central, lo que motivó migraciones en busca de nuevas tierras donde impulsar el sistema parcelario y el cultivo de café (Gudmundson, 1979), pero también alimentado por un grupo cada vez más importante de migrantes que se desplazaban en busca de tierras, debido a la dinámica de concentración que se desarrolló, particularmente, luego de la llegada del capital comercial británico y de que la tierra se transformara en una mercancía más.

En esencia, de esta dinámica poblacional en zonas como Guanacaste es relevante porque refleja que la costa del Pacífico no era un espacio despoblado pese a que, en muchos trabajos, se alega la existencia de grandes haciendas de propietarios ausentistas. Por el contrario, esa población necesariamente requería apropiarse de manera directa de los recursos naturales, particularmente de leña para los hogares, pero también de maderas para la construcción de graneros, así como de cercas y corrales para el ganado, de tal forma que se pudiesen separar de las áreas de cultivo. En otras palabras, parece claro que, durante la segunda mitad del siglo XIX, el crecimiento de la población en regiones costeras como las del Golfo de Nicoya, unido al paulatino agotamiento de las maderas finas, supuso una transformación sustancial de la relación socioecológica que había prevalecido hasta entonces, transición que permitió pasar de un sistema netamente extractivista de recursos de la naturaleza a otro donde el agroecosistema se presenta como un espacio diversificado con una clara orientación al autoconsumo familiar.

Ahora bien, la percepción de Calvo citada coincide con lo apuntado por Jorge León al indicar que "a la explotación de ganadería extensiva de estas haciendas, se unió hacia 1880 la explotación en gran escala de madera en bruto para exportación, aunque su mayor expansión ocurrió en la década posterior de 1890" (León 2012, 51). Según León, esto se debió a que el interés hacia la ganadería por parte de "capitalistas del Valle Central así como extranjeros, necesariamente llevaba a convertir el bosque natural en pastos, es decir, la corta de madera era una etapa previa a la siembra de pastos". Pero, además, citando los estudios de Gudmunson y de Sequeira, León afirmaba incluso que

La existencia en estos bosques de árboles de maderas finas (caoba, cedro, etc.), muy valoradas debido a la gran demanda para fabricar muebles en los mercados de Gran Bretaña y Alemania, incluso llegó a convertir a la extrac- 
ción de madera para exportación en la actividad comercial principal y sus ingresos se utilizaron para financiar el posterior desarrollo de la ganadería (León 2012, 54).

Esta circunstancia retratada por León es fundamental de rescatar, pues como él mismo lo indica, muchos cafetaleros decidieron invertir parte de sus ganancias en actividades comerciales, otros se convirtieron en banqueros y "Algunos más, invirtieron en tierras que se estaban haciendo accesibles en el litoral del Caribe y en Guanacaste, donde respectivamente fue posible establecer explotaciones del banano y de maderas finas" (León 2012, 70). Justamente, la construcción de la línea férrea que comunicaría el Valle Central con la costa del Caribe se convirtió, desde la década de 1870, en otro foco de referencia para la explotación de maderas, tanto en las zonas que se debían despejar para la construcción del tendido ferroviario como en las propiedades cedidas por el Estado a Minor Keith a cambio de la construcción de la obra; tierras que también empezaron a desmontarse para dar paso a lo que se conocería como el enclave bananero.

Ahora bien, tener clara esta explotación de maderas, tanto del Pacífico como del Caribe, también es relevante en la medida que el negocio de la madera incentivó otras actividades como la ebanistería. Según lo documentado por Calvo $(1886,105)$, para entonces, en Costa Rica se registraban 72 máquinas de aserrar, cepillar y labrar madera, así como 125 talleres de carpintería y ebanistería $^{10}$. Sin lugar a duda, este conjunto de oficios relacionados con la transformación del recurso forestal resultó de vital importancia e incidió de forma directa en la construcción de hogares, puentes, línea férrea, almacenes, infraestructura escolar, entre muchos otros usos. A esto contribuyó la creación de caminos en la segunda mitad del siglo y un poco más tarde el mismo ferrocarril.

La madera que se extraía de los bosques nacionales se exportaba principalmente en trozas (lo que hoy se denomina madera rolliza) y como se señaló, esta actividad creció hasta convertirse en un significativo rubro de las exportaciones y ocupar un impresionante tercer lugar en 1885, como se aprecia en la tabla 1.

10. Lamentablemente, los datos sobre instalaciones de procesamiento de madera son limitados, lo que dificulta para este periodo hacer una lectura más puntual sobre su desarrollo.

Tabla 1. Valor de los principales 5 productos de exportación costarricense entre 1884 y 1885 (en pesos de la época)

\begin{tabular}{lcc}
\hline \multicolumn{1}{c}{ Producto } & $\mathbf{1 8 8 4}$ & $\mathbf{1 8 8 5}$ \\
\hline Café & 3615113,20 & 2486643 \\
Racimos de banano & 336000 & 302457 \\
Madera en trozas & 47252 & 102573 \\
Cuero de res & 71548,58 & 79374 \\
Caucho & 68020,83 & 33265 \\
\hline
\end{tabular}

Elaboración propia con base en Calvo $(1886,110)$. 
El resultado de este activo comercio de madera ocasionó que se volvieran los ojos al potencial que tenían algunas zonas del país. En 1886, por ejemplo, se señalaba que apenas se terminara la canalización de los ríos y esteros entre el río San Juan y Matina, se podría explotar "sus vastísimos cocales, sus maderas y otros muchos elementos de riqueza que ofrece aquella zona al comercio universal" (Calvo 1886, 132).

Cuadro 1. Maderas utilizadas en Costa Rica para ebanistería y construcción a finales del siglo XIX

\begin{tabular}{|c|c|c|c|}
\hline \multicolumn{2}{|c|}{ Maderas de ebanistería } & \multicolumn{2}{|c|}{ Maderas de construcción } \\
\hline Albahaquilla & Forestiera cartaginensis & Agüilla & Hedyosmum costaricense \\
\hline Brasil & Haematoxylum brasiletto & Almendro & Dipteryx oleifera \\
\hline Canela & Ocotea atirrensis & Caragra & Lippia myriocephala \\
\hline Caoba & Swietenia macrophylla King & Cedro macho & Brunellia costaricensis \\
\hline Carboncillo & Albizia carbonaria & Chirraca & Myroxylon balsamum \\
\hline Cedro dulce & Cedrela tonduzii & Copalillo & Protium glabrum \\
\hline Cedro amargo & Cedrela odorata & Corteza blanca & Godmania aesculifolia \\
\hline Cocobola ñambar & Dalbergia retusa & Cuerillo & Peltanthera floribunda \\
\hline Cocobola negro & $\ldots$ & Curá & Viburnum costaricanum \\
\hline Cherre & $\ldots$ & Danto hediondo & Roupala montana \\
\hline Chirraca & Myroxylon balsamum $L$ & Encina & Quercus lancifolia \\
\hline Corteza amarilla & Tabebuia ochracea & Guachipelín & Diphysa americana \\
\hline Corteza negra & Tabebuia impetiginosa & Granadillo & Dalbergia glomerata \\
\hline Corazón de león & $\ldots$ & Guaitil & Genipa americana \\
\hline Granadillo & Dalbergia melanoxylon & Ira colorado & Nectandra cufodontisii \\
\hline Guayacán & Guaiacum sanctum & Ira mangle & Ocotea endresiana \\
\hline Guácimo & Guazuma ulmifolia & Jaúl & Alnus acuminata \\
\hline Guayabo & Terminalia oblonga & Lagarto & Zanthoxylum ekmanii \\
\hline Guayabillo & Psidium sartorianum & Lantizco & Mauria heterophylla \\
\hline Laurel & Cordia alliodora & Laurel & Cordia alliodora \\
\hline Loro & Dilodendron costaricense & Madera-hierro & Gordonia fruticosa \\
\hline Llorón & Cornus disciflora & Naranjillo & Hyperbaena tonduzii \\
\hline Melón & $\ldots$. & Níspero & Manilkara zapote \\
\hline Moral & Chlorophora tintora & Ñambar & Dalbergia glomerata \\
\hline Níspero & Manilkara zapote & Pavilla & Lonchocarpus costaricensis \\
\hline Papa & $\ldots$ & Pipa & $\ldots$ \\
\hline Papaturro negro & Coccoloba padiformis & Plomillo & Caryocar costaricense \\
\hline Quiebra-hacha & Lysiloma divaricatum & Quizarrá & Croton schiedeanus \\
\hline Quizarrá amarillo & Ocotea haberi & Roble negro & Tabebuia impetiginosa \\
\hline Quizarrá negro & $\begin{array}{l}\text { Rhodostemonodaphne } \\
\text { kunthiana }\end{array}$ & Ronrón & Astronium graveolens \\
\hline Roble & Quercus copeyensis & Tiquisirrí & Styrax argenteus \\
\hline Ronrón jaspeado & $\ldots$ & Zapotillo & Lucuma campechana \\
\hline San Juanillo & Mahonia paniculata & & \\
\hline Sirrí & Tapirira mexicana & & \\
\hline Tres huevos & Cupania glabra & & \\
\hline
\end{tabular}

Elaboración propia con base en Calvo $(1886,41-42)$. Se respeta la escritura de los nombres comunes o vernáculos. Los nombres científicos tienen un carácter aproximado pues la fuente original no contiene las referencias y los inventarios disponibles no permiten precisarlos. 
Y es que, entre abril de 1894 y marzo de 1895, la exportación de palo de mora, cocobolo, cedro y caoba realizada solo por el puerto de Puntarenas, le reportó al erario la suma de 19689,90 pesos en impuestos (Montealegre $1895,123)^{11}$.

Por otro lado, aunque el territorio costarricense no se había explorado en su totalidad, ya se tenía conocimiento de una amplia variedad de maderas que, por su dureza y resistencia, eran valoradas como de uso adecuado para diferentes trabajos de construcción.

\section{La deforestación en el epílogo del siglo XIX}

Como es de suponer, este activo comercio y uso de la madera originó repercusiones sobre la cobertura natural del territorio, particularmente en el Valle Central. Entre las fuentes que permiten un acercamiento a esa realidad de finales del siglo XIX están las descripciones recogidas en la revista Anales del Instituto Físico-Geográfico Nacional por parte de Henri Pittier ${ }^{12}$. Solo como ejemplo se citan dos alusiones a este tema. La primera de ellas, realizada en 1890, corresponde a la publicación de un estudio de la fitogeografía centroamericana escrito por el Dr. Polakowsky ${ }^{13}$, según la cual "La selva virgen a desaparecido y en su lugar vienen plantaciones de café, de maíz y de caña de azúcar, ó extensos pastos", a lo que agregaba que "Las selvas vírgenes sólo se ven en las serranías que forman las orillas de las altiplanicies" (Pittier 1890, 188). Dos años más tarde, se publicó el Viaje de Exploración al Río Grande de Térraba, elaborado por Pittier, en el cual se indicaba que

En estos últimos años, se han tumbado muchas partes de los robledales de las cimas del Tablazo y, al ver el progreso de esta insensata destrucción, el que está formalizado con los terribles efectos de los desmontes en otros países, vuelve involuntariamente á pensar en el día en que la hermosa meseta central de Costa Rica se vea despojada de su corona de selvas y privada de sus cursos de agua. Ojalá el actual Gobierno, celoso en fin de uno de los mayores intereses de las poblaciones, ponga término á la exterminación imperdonable que se sigue practicando de los pocos bosques que orlan todavía la meseta central. Es inconcebible que, á pesar de haberse señalado tantas veces la inminencia del peligro, se siga permi-
11. Para ese momento, el peso estaba equiparado con el dólar.

12. En algunos documentos, se firmaba como Enrique Pittier; en otros, la escritura del nombre aparece como Henry.

13. La obra fue traducida del alemán por Manuel Carazo Peralta y anotada [comentada] por H. Pittier. Según Pittier, este estudio publicado en 1879 en Alemania constituye "el resumen más completo que se haya escrito hasta la fecha acerca del estado de nuestros conocimientos sobre la flora de la patria centro-americana". 
tiendo las quemas de los bosques en la meseta y en su contorno (Pittier 1892, 61-62).

De esta acotación de Pittier, interesa rescatar de momento una frase que puede pasar desapercibida, pero que claramente refiere a la ubicación de los remanentes de bosque en el Valle Central en lo que denomina "su corona de selvas". Goebel $(2006,18)$ señala que Pittier se convirtió en uno de los principales denunciantes de la deforestación. Sin embargo, esta preocupación de Pittier parece restringirse solo a las cercanías de la "meseta central", pues, conforme prosigue su descripción del viaje, decía que:

la mayor parte del territorio del que vamos tratando está cubierto de extensas selvas que abundan de maderas finas y de construcción, así como también en hule, plantas medicinales, textiles, etc. Dada la abundancia de las aguas que permite en todas partes el establecimiento de máquinas adecuadas, la explotación de aquellos bosques podría hacerse con facilidad por cuanto haya posibilidad de llevar las maderas á la costa (Pittier 1892, 102).

Esta aparente contradicción de Pittier la explica de forma clara Goebel (2008, 20-21), al señalar que el explorador suizo intercalaba, en su discurso, elementos propios de un "conservacionismo utilitario" y otros relacionados con la ecoeficiencia como, por ejemplo, la explotación racional de los recursos. Pero justamente esta dualidad de percepciones sobre la necesidad de proteger áreas de bosques o talarlas, se mantuvo hasta bien entrado el siglo XX y ello favoreció que la sociedad costarricense entrara en dicha centuria con un claro daño ambiental, provocado por la deforestación desmedida principalmente en el Valle Central y el Pacífico Norte. También, es necesario tomar en cuenta que la existencia de frontera agrícola y la apertura paulatina de caminos hacia diferentes partes del territorio favoreció una dinámica de explotación de los recursos del bosque cada vez en mayor escala. Y, además, que la inexistencia de leyes o el poco cumplimiento de las escasas normas dictadas también posibilitó que los bosques fuesen dando paso a pastizales, áreas de cultivo o simplemente a bosques degradados.

En este abordaje es oportuno dejar claro, también, que las ideas de progreso liberal de finales del siglo XIX, impulsadas por el Estado para regular la explotación de recursos naturales, demarcaron las primeras líneas de lo que en el siglo siguiente serían las políticas conservacionistas. Al respecto, Goebel $(2008,25)$ sugiere que las

acciones concretas destinadas a la protección de recursos naturales en Costa Rica, parecen haber tenido su ori- 
gen en la confluencia de un ambientalismo "desde abajo", detectable al menos desde los albores de la independencia, guiado por las protestas y denuncias de distintos grupos sociales por su exclusión y/o marginación en la distribución ecológica en el tanto les privaba de recursos necesarios para su subsistencia, y un ambientalismo "desde arriba", que adquiere mayor visibilidad en el epílogo decimonónico, sustentado en la conservación de recursos considerados estratégicos para el Estado de acuerdo a su noción de progreso y las nuevas corrientes conservacionistas que señalaban la necesidad de una administración racional de los recursos como medio para perpetuar su uso y explotación.

Reafirmar que este interés del Estado por regular y controlar la explotación de recursos, por ejemplo, vía contratos, estaba sustentado principalmente en la necesidad de asegurarse el control aduanero y el cobro de los impuestos de exportación de maderas. Al respecto, Goebel es contundente al señalar que

el Estado parece haber sido un activo socio en la explotación de los bosques. El obtener réditos de los contratos de explotación forestal en los baldíos y bosques nacionales, era un fin primordial del Estado y sus aventajados socios comerciales nacionales y extranjeros. En virtud de lo anterior consideramos que buena parte de la legislación "conservacionista" decimonónica -al igual que la actualtenía como fin último ejercer un control efectivo de los recursos naturales, y que estos no fueran explotados sin beneficio alguno para el erario público (Goebel 2013, 76).

No obstante, como ya se indicó, la escasez de personal, por un lado, y la existencia de gran cantidad de sitios adecuados para establecer embarcaderos, por otro, principalmente en la costa del Pacífico, parece haber favorecido la explotación irracional y la evasión del pago de los impuestos. En este sentido, pareciera que ese ambientalismo "desde abajo", si realmente llegó a operar, lo hizo en el Valle Central, no así en las costas del Pacífico y del Cari- 
be, donde el poco control estatal se confabulaba con la "inmensidad del bosque" para resguardar la tala y exportación ilegal de maderas nacionales.

\section{Algunas palabras de cierre}

Este recuento, aunque breve, deja claros aspectos fundamentales que contribuyen a explicar el proceso de deforestación que ha experimentado el territorio costarricense desde 1821. Por un lado, debe entenderse que se trata de un proceso asociado a la ocupación del territorio producto de la expansión de la frontera agrícola y al desarrollo de la agricultura del café y, por otro, que este proceso de deforestación fue impulsado-promovido por el Estado mediante distintas leyes que intentaban regular/impulsar la explotación de maderas finas de los bosques nacionales. El interés por este control estuvo sustentado, primero, en la necesidad de asegurarse el cobro de impuestos, y, en segundo lugar, por percepciones relacionadas con un conservacionismo utilitario (en el sentido expresado por Goebel) e incluso con "esbozos" de un incipiente ecologismo de los pobres o ecologismo "desde abajo", al estilo de lo propuesto por Joan Martínez Alier (2005), lo cual se aprecia en las denuncias hechas por comunidades y representantes municipales.

Además, este proceso de deforestación tuvo dos flancos de avance. Uno con características centrífugas que fue extendiéndose desde el Valle Central hacia la periferia, alimentado tanto por la apertura de caminos como por la creación-instalación de una industria de transformación de la madera asociada a la ebanistería y la construcción, lo cual incluso llevó a que se planteara la escasez de leña necesaria para los hogares. Pero, por otro lado, la tala de maderas finas con propósitos de exportación se acentuó sobre todo en las costas del Pacífico Norte y se extendió por todo el litoral gracias a la posibilidad de establecer embarcaderos en la costa. En este último caso, la explotación estuvo condicionada, hasta cierto punto, por la cercanía entre los sitios de tala y la costa, pero esta limitación se fue superando con la apertura de caminos, tanto hacia el Pacífico (Norte y Sur) como hacia el Caribe (vinculado a la explotación bananera). El uso de la madera local incluyó una amplia variedad de especies forestales, pero la exportación, al menos durante el siglo XIX, se concentró en especies como cocobolo, caoba y cedro, principalmente.

Es necesario comprender que el "coste" o la "escala" de este proceso de deforestación durante el siglo XIX fue muy diferente al que tendría en el siglo XX. No obstante, el impacto regional, específicamente en Guanacaste, el Valle Central y en menor medida en el Pacífico Central, permiten explicar por qué la explotación y exportación de maderas en el siglo XX se centró, en particular, en la Zona Norte y Caribe del territorio. Incluso la variedad de maderas que se exportaron en la primera mitad del siglo $X X$ puede entenderse como una manifestación de la escasez de ciertas especies forestales, aunque, como es obvio, también incidió la demanda de variedades útiles para otros usos como contrachapados y celulosa de papel. En este sentido, el trabajo de Goebel es útil para entender la dinámica que el mercado de la madera le imprimió al proceso de explotación forestal. 
De manera consecuente, es fundamental reconocer que la deforestación no es un fenómeno propio del siglo $\mathrm{XX}$ y que tampoco es un proceso ligado exclusivamente a la ganadería y a la transformación de la frontera agrícola, como se ha visto en algunos escritos. En este sentido, resulta útil revisitar los trabajos de Molina (1988), Gudmundson (1979), Acuña y Molina (1986), así como el de Samper (2003), entre otros, en los cuales se abordan las transformaciones experimentadas en los inicios del capitalismo agrario y, como resultado de este, en la segunda mitad del siglo XIX. Por ejemplo, Molina (1988, 85-88) hace un recuento interesante sobre las luchas por la conservación de las tierras comunales en el Valle Central en el contexto donde estas empezaban a desaparecer para dar paso a la propiedad privada, dinámica que posiblemente incentivó migraciones hacia las zonas de frontera, alentados no solo por la tierra, sino también por la posibilidad de aprovechar las maderas.

De hecho, Gudmundson (1979), en la crítica al trabajo de Mitchell Seligson sobre el capitalismo agrario en Costa Rica, señala que más allá del crecimiento poblacional o del fenómeno de la proletarización que se achaca comúnmente a la expansión cafetalera, la migración estuvo en parte alimentada por las oportunidades que abrió el cultivo de café y la idea de muchos de expandirse hacia la periferia del Valle. Sin embargo, aunque Gudmundson $(1979,81)$, en ese mismo trabajo, señala que las migraciones hacia Guanacaste se dieron hasta finales del siglo XIX y en particular hacia las zonas altas de Tilarán para continuar el sistema parcelario y cafetalero del Valle Central, lo cierto es que al menos en decreto, el Estado, desde 1840, estaba impulsando la colonización de las áreas cercanas al Golfo de Nicoya.

Aunque el debate sobre el impacto del capitalismo agrario no se ha cerrado, los aportes de estos autores permiten asegurar que la combinación de factores como la privatización de baldíos y tierras comunales, la metalización de la economía, la existencia de crédito y el éxito del comercio del café crearon las condiciones necesarias para que muchos decidieran migrar en busca de nuevas tierras y oportunidades. Pero también es posible que otros decidieran invertir en nuevas actividades como la explotación maderera, pues, como vimos, desde mediados de siglo XIX se practicaba en las costas guanacastecas para exportar hacia países como Perú. Asimismo, la ocupación del espacio y la inclusión de nuevas actividades agrícolas modificó cualitativamente la relación socioecológica, de tal manera que la explotación de los recursos forestales pasó a convertirse paulatinamente en una importante fuente de ingresos, particulares y estatales, como lo revela Goebel en su investigación.

Quizás más importante que la deforestación misma, es relevante destacar que, en el marco de este proceso, la sociedad costarricense de un lado y las autoridades del otro comienzan a darse cuenta de la necesidad de proteger los bosques. Las manifestaciones que asociaban la tala con la falta de lluvias, con el problema del suministro de aguas y con la carestía de maderas son ejemplos claros de que algunos sectores de la población empezaban a reconocer la necesidad de una legislación para proteger los bosques, aunque detrás de esto estaba solo el sentido utilitario. Ninguna de estas situaciones motivó cambios significativos y, por el contrario, el siglo XX enfrentó al país a 
14. En otro artículo que está en proceso, se aborda el periodo 1900-1950, como continuación de este análisis sobre el proceso de deforestación en Costa Rica. situaciones que, lejos de evitar el continuo deterioro de la cobertura forestal, lo acentuaron, al menos hasta la década de 1980 cuando se declara la crisis forestal en el país ${ }^{14}$, pese a la Ley Forestal decretada en 1969.

\section{Bibliografía}

Acuña, Víctor Hugo e Iván Molina. 1986. El Desarrollo económico y social de Costa Rica: de la colonia a la crisis de 1930. San José, Costa Rica, Editorial Alma Mater.

Boza Loría, Mario A. (2015). Historia de la Conservación de la Naturaleza en Costa Rica 1754-2012. Cartago, Costa Rica. Editorial Tecnológica.

Calvo, Joaquín Bernardo. 1886. Administración Soto (Bernardo): Apuntamientos geográficos, estadísticos e históricos de Costa Rica. San José, Costa Rica, Imprenta Nacional.

Edelman, Marc. 1998. La lógica del latifundio: las grandes propiedades del noroeste de Costa Rica desde fines del siglo XIX. Traducción de Jeanina Umaña Aguilar. Editorial de la Universidad de Costa Rica. Stanford University Press.

Goebel, Anthony. 2006. «Ciencia, legislación y discurso conservacionista. El "germen" de los Parques Nacionales en Costa Rica: Elementos conceptuales y "matices" analíticos 1833-1955». Diálogos Revista Electrónica de Historia. Volumen 6 Número 2. 1-39. Acceso 15 de noviembre de 2018. https://revistas.ucr.ac.cr/index.php/dialogos/article/view/6224

Goebel, Anthony. 2008. «La naturaleza entre lo inmaculado, lo productivo y lo necesario. Hacia una "historización" de los conceptos, prácticas y representaciones conservacionistas en los exploradores de la Costa Rica decimonónica». Diálogos Revista Electrónica de Historia. Vol. 9. Número especial. $9^{\circ}$. 1-40. Congreso Centroamericano de Historia. Acceso 15 de noviembre de 2018. https://revistas.ucr.ac.cr/index.php/dialogos/article/view/31020

Goebel, Anthony. 2013. Los bosques del progreso: explotación forestal y régimen ambiental en Costa Rica, 1883-1955. San José, Costa Rica, Editorial Nuevas Perspectivas.

Gudmundson K. Lowell. 1979. «Apuntes para una historia de la ganadería en Costa Rica, 1850-1950». Revista de Ciencias Sociales. N. ${ }^{\circ}$ 17-18. 61 81. San José, Universidad de Costa Rica (UCR).

Gudmundson, K. Lowell. 1979. «El campesino y el capitalismo agrario en Costa Rica: Una crítica de ideología como Historia». Revista de Historia. Año IV, Número 8. Heredia, Costa Rica, Escuela de Historia. 
Hall, Carolyn. 1991. El café y el desarrollo histórico-geográfico de Costa Rica. San José. Editorial Costa Rica.

León Jorge. 2012. Historia económica de Costa Rica en el siglo XX. Tomo II: la economía Rural. San José, Costa Rica. Universidad de Costa Rica, IICE, CIHAC.

Martínez Alier, Joan. 2005. El ecologismo de los pobres. Barcelona, España. Icaria Editorial.

Molina, Felipe. 1851. Bosquejo de la República de Costa Rica seguido de apuntamientos para su historia. Nueva York, imprenta de S.W. Benedict, №. 16 calle de Spruce.

Molina, Iván. 1988. La alborada del capitalismo agrario en Costa Rica. San José Costa Rica. Editorial Universidad de Costa Rica.

Montealegre, Ricardo. 1895. Memoria de Hacienda y Comercio presentada al Congreso Constitucional. San José, Costa Rica. Tipografía Nacional.

Pérez Brignoli, Héctor. 1988. «Reconstrucción de las estadísticas parroquiales de Costa Rica, 1750-1900». Revista de Historia, Número 17. 211-277. San José, Costa Rica.

Pittier, Henri. 1890. «La Flora de Costa Rica. Contribución al estudio de la Fitogeografía centro-americana por el Dr. Polakowsky». Anales del Instituto Físico-Geográfico y del Museo Nacional de Costa Rica. Tomo II-2da parte 1889. 177-201. Traducido del alemán por Manuel Carazo Peralta y anotado por H. Pittier. San José, Costa Rica, Tipografía Nacional.

Pittier, Henri. 1892. "Viaje de exploración al Valle del río Grande de Térraba». Anales del Instituto Físico-Geográfico y del Museo Nacional de Costa Rica. Tomo III-1890. 3-94. San José, Costa Rica, Tipografía Nacional.

Samper K. Mario. 2003. «Tierra, trabajo y tecnología en el desarrollo del capitalismo agrario en Costa Rica». Revista de agricultura e historia rural, 29. España.

Sancho González, Eduardo. 1972. «Las funciones municipales (artículo 4 del Código Municipal) y la realidad municipal costarricense». Revista de Ciencias Jurídicas, Núm. 20-21. 63-103. Acceso el 10 de octubre de 2018.

https://revistas.ucr.ac.cr/index.php/juridicas/article/view/16666/16171

Sequeira Ruiz, Wilder G. 1985. La hacienda ganadera en Guanacaste: aspectos económicos y sociales 1850-1900. San José, Costa Rica, EUNED.

Zúñiga, Tobías. 1904. Memoria de Hacienda y Comercio presentada al Congreso Constitucional. San José, Costa Rica. Tipografía Nacional. 